\title{
Culturally Specific Evaluation of Inhaler Techniques in Asthma
}

\author{
Iraj Poureslami PhD, Jessica Shum, Laura Nimmon PhD, and J Mark FitzGerald MD
}

\begin{abstract}
BACKGROUND: Little work has been done on identifying the impact of educational materials developed by immigrant patients themselves, along with their caregivers and health professionals in terms of inhaler use technique. The purpose of this study was to evaluate understanding of physicians' instructions on asthma management and inhaler techniques in Punjabi and Chinese subjects using educational interventions in their native languages. METHODS: Eighty-seven subjects with asthma were randomly assigned to either one of 3 experimental groups (physician-led video, subject-generated community video, or both) or a control group (educational pamphlet). Medication knowledge and inhaler skills were measured during 3 in-person interviews. RESULTS: Subjects in all 3 experimental groups, when compared with control subjects, demonstrated improvements in the follow-up test in terms of ability to use inhalers correctly $(P<.001)$ and understanding of physicians' instructions $(P=\mathbf{. 0 0 8})$. Chinese participants showed significantly greater improvements compared with Punjabi participants for the correct use of inhalers $(P<.047)$, and females showed greater improvements compared with male subjects $(P=.04)$. CONCLUSIONS: The educational interventions developed were successful in behavioral modification and beneficial beyond usual care in terms of improving proper use of inhalers and understanding of physicians' instructions. The findings can be translated to health education practice, promoting the development of short, simple, and culturally linguistically appropriate learning materials for patients. Such interventions that draw on patients' life experiences and socio-cultural context can overcome certain limitations of conventional patient education approaches. (ClinicalTrials.gov registration NCT01474928.) Key words: asthma; inhaler technique; educational intervention; cultural background; instructional videos; patient engagement. [Respir Care 2016;61(12):1588-1596. (C) 2016 Daedalus Enterprises]
\end{abstract}

\section{Introduction}

Up to $60 \%$ of patients with asthma use their inhalers incorrectly. ${ }^{1,2}$ Moreover, instructions on how to properly

Dr Poureslami and Ms Shum are affiliated with the Faculty of Medicine, Respiratory Medicine Division, Centre for Clinical Epidemiology and Evaluation (C2E2), University of British Columbia, Vancouver, Canada. Dr Nimmon is affiliated with the Faculty of Population and Public Health, University of British Columbia, Vancouver, Canada. Dr FitzGerald is affiliated with the Institute for Heart and Lung Health, Faculty of Medicine, Respiratory Medicine Division, University of British Columbia, Vancouver, Canada.

Supplementary material related to this paper is available at http:// www.rcjournal.com.

This work was funded by the Canadian Institutes of Health Research (CIHR) and partly by the Centre for Lung Health at the University of British Columbia. The authors have disclosed no conflicts of interest. use inhalers reach only a small portion of non-Englishspeaking ethnic communities, ${ }^{3}$ leading to poor inhaler technique, which can result in reduced lung deposition of the active drug, ${ }^{4}$ less well controlled symptoms, ${ }^{5}$ more air flow obstruction, ${ }^{6}$ higher cost for the patient and society, ${ }^{6-9}$ and potentially worse adherence. ${ }^{10}$ This is mainly because a majority of health information in Canada is presented in English/French and uses highly technical medical terms, making it difficult to understand and follow for patients from ethno-cultural communities. ${ }^{11-13}$ In some instances, program developers/researchers attempt to trans-

\footnotetext{
Correspondence: J Mark FitzGerald MD, Institute for Heart and Lung Health, 7th Floor, Gordon and Leslie Diamond Health Care Centre, 2775 Laurel Street, Vancouver, British Columbia V5Z 1M9, Canada. E-mail: mark.fitzgerald@vch.ca.
}

DOI: $10.4187 /$ respcare. 04853 
late the information into different languages. ${ }^{14-16}$ However, direct translation from English to another language is usually not enough to make health information culturally appropriate. ${ }^{17}$ When members of patient populations and their home caregivers are involved in the development of information materials and educational interventions, these materials are perceived as more culturally relevant and more meaningful to patients. ${ }^{18,19}$ Therefore, to create relevant and accessible informational materials, specific attention should be focused on variability in levels of health literacy and cultural beliefs and practices of the involved patients. ${ }^{20}$ The impact of educational materials developed with the involvement of immigrant patients, their home caregivers, and health professionals on asthma self-management has been understudied.

The main objective of this study was to improve inhaler technique and subject understanding of physicians' treatment-related instructions by using culturally and linguistically appropriate educational interventions. Secondary objectives were to assess: (1) whether involvement of subjects, home caregivers, and clinicians in the development of appropriate information content would be associated with better understanding of given information; (2) whether subjects exposed to videos show better skill attainment than those exposed to print materials; and (3) whether skill attainment differs by source of information (physician-led vs subject role-played). Our hypothesis was that subjects who received information via the physician-led video would show significant improvements in their inhaler skills and understanding of physicians' instructions compared with the other groups.

\section{Methods}

\section{Design}

The research applied both qualitative and quantitative methods, including a full participatory approach. The study was conducted at a university-based pulmonary medicine clinic. It was approved by the University of British Columbia Office of Research Ethics and was registered at ClinicalTrials.gov. All subjects signed a written consent form in their native language before the study.

\section{Study Participants}

We enrolled subjects who had a physician diagnosis of asthma, used asthma medications daily, were $\geq 21$ y old, had immigrated to Canada within the past $5 \mathrm{y}$, resided in Vancouver during the study period, and spoke Mandarin, Cantonese, or Punjabi. A convenience sampling method was applied, and 167 adults with asthma were recruited, of whom 35 participated in the development of the educational videos and pamphlets, 40 participated in initial fo-

\section{QUICK LOOK}

\section{Current knowledge}

Asthma tends to be less controlled among immigrants and low-income groups in Canada, including Chinese- and Punjabi-speaking communities. Many patients with asthma use their inhalers incorrectly, and poor inhaler technique is especially common among less educated and immigrant groups. Research has shown that people learn better when provided with audiovisual education materials, and immigrant patients understand treatment instructions better when taught in their native language.

\section{What this paper contributes to our knowledge}

Culturally and linguistically appropriate interventions can promote asthma subjects' understanding of physicians' recommendations and improve their inhaler skills and can be sustained over the short term. Such interventions that provide authentic learning materials that draw on the patients' life experiences and socio-cultural context can overcome certain limitations of conventional patient education approaches.

cus group sessions to review and comment on the educational materials and the study design and procedures, and the remaining 87 subjects participated in the educational intervention (85 completed all study assessments). The 75 subjects who participated in either focus groups or the development of educational materials were not invited to participate in the study intervention (Fig. 1). All study participants were identified and directly recruited from the collaborating physicians' clinics.

Since we had 4 groups in the study, we needed a total of 6 comparisons between the 4 groups. To guarantee an overall type- 1 error of .05 , each comparison needed to be carried out at (approximately) a type-1 error of .01 (2-sided). This means that each comparison would have identified as significant a difference between the 2 group means of $\mathrm{d}(\mathrm{t})=1.05 \mathrm{SD}$, at a power of approximately $80 \%$.

\section{Measurements}

Due to the absence of a validated assessment questionnaire in the target languages, a new measurement tool was developed by the study team as an integral part of this study. The developed instrument was pilot-tested with a number of subjects with asthma and validated (in terms of face and content validation) by participants' and professionals' inputs. Subjects' skills specific to the appropriate use of inhalers were assessed by direct observation. Participants were asked to demonstrate the use of an inhaler 


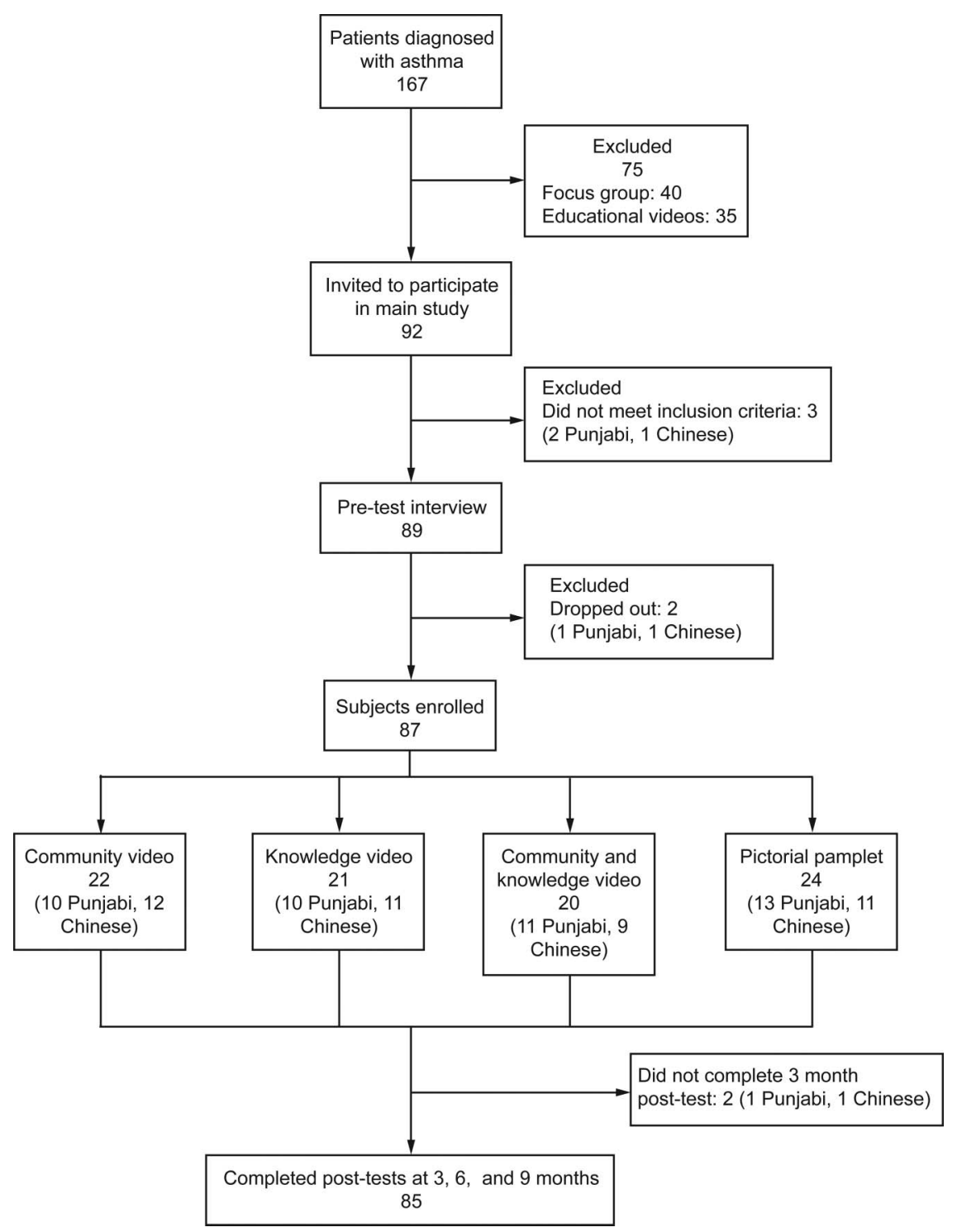

Fig. 1. Flow chart.

and to describe the steps they were taking in doing so. The measure was the percentage of correct steps in inhaler use, applying standard checklists. ${ }^{21,22}$ For participants using $\geq 2$ inhalers, the success rate was the percentage of correct steps taken across all inhalers. Scoring for these questions was from 0 to 9 , with a 0 score meaning the subject missed all the necessary steps for inhaler use and a 9 score meaning the subject used all 9 steps of the inhaler technique appropriately. The 9 steps were: (1) shake device (metered-dose inhaler); (2) load the inhaler; (3) breathe out away from inhaler; (4) put the inhaler in mouth behind teeth; (5) breathe in deeply; (6) hold breath for 5-10 s; (7) breathe out from nose; (8) wait for $60 \mathrm{~s}$ before taking the second puff, if needed; and (9) recap and rinse mouth, if needed. The study questionnaire was designed using the Canadian Thoracic Society guidelines. ${ }^{23}$ This instrument also included 5 practical outcome items to assess subjects' understanding of and adherence to their physician's instructions. For instance, we asked the participants: "Imagine your doctor has instructed you to take 2 inhalations twice daily in the morning and evening (approximately $12 \mathrm{~h}$ apart). Also, continue to use your reliever inhaler on an as-needed basis. Can you explain in your own words what this instruction means to you"? Scores for these questions were 0 and 1 , with a score of 0 meaning the subject incorrectly answered and a score of 1 meaning that the subject correctly answered the questions.

\section{Education Materials Development}

Based on 4 preliminary patient-oriented focus group sessions conducted in 2008 as well as an earlier systematic 
review with regard to the relationship between health literacy and asthma outcome in ethnic minority groups, ${ }^{20,24,25}$ we developed 2 sets of educational videos (physician-led and community videos) and pictorial pamphlets for each community. The culturally specific educational materials, 2 videos and one pamphlet, used as interventions in this study were developed by this research team using a community-based participatory approach that actively involved subjects from the Greater Vancouver Chinese and Punjabi communities in their development and testing. To ensure that the content of materials was equivalent across all 3 languages, we developed the written materials (control pictorial pamphlet) in English first and then asked professional community-based translators to translate the information, as well as provide back-translation, to the 3 target languages. The same content was used to develop the videos. In designing our videos, we elected to create 2 versions to allow for a comparison of the effect of instructions provided by lay people (subjects and home caregivers) or physicians and to explore whether any added advantage arose from exposure to both sources of information. In the community video, subjects and caregivers role-played a scenario, offering opinions and narratives about asthma and its management in short (12-14-min) videos. The physician-led video was relatively long $(25 \mathrm{~min})$ and provided clinical information about asthma symptoms, medication techniques, and self-management strategies. Well-known physicians from the same ethnic background who had previous experience in educating patients via video format were invited to the study who then volunteered to perform in the physician-led videos. Content for the community videos and physician-led videos was similar, with the only difference being that one was provided by the lay community. Cultural beliefs and practices from the 3 target ethnicity communities were also applied in the community videos. The correct way of using inhalers was performed by respiratory educators from the target communities at the end of both the physician-led and community videos. All materials were produced in Mandarin, Cantonese, and Punjabi. More information on the development of our asthma educational materials can be found in our previous articles. ${ }^{24-26}$ Links to the copyrighted videos and educational illustrations are provided in the online supplementary materials at http://www.rcjournal.com.

\section{Intervention Procedures}

The study intervention lasted for 10 months. The baseline assessment (pretest) preceded the intervention; the postintervention assessment occurred immediately following the intervention ( 1 month after the baseline assessment); and a subsequent assessment (follow-up test) occurred 3 months following intervention. Data collection was conducted by trained bilingual facilitators, who were blinded to the study hypothesis. After the initial pretest interviews, 87 subjects were randomly assigned to one of 4 study groups, and of these, 85 completed the study. The intervention consisted of a single exposure to educational materials. Group $1(n=22)$ was assigned the physicianled video; Group $2(n=21)$ watched the community video; Group $3(n=20)$ watched both videos; and Group 4 $(n=22)$ served as the control group and read the pamphlet. Subjects watched the video(s) or read the pamphlet a single time, at a location of their choice (clinic or home). The study team was not blind to the subject group assignment. We also involved a family member who normally took care of the subject at home (the immediate caregiver at the home) in the interviews and learning process across the study groups. The attendance of the immediate caregiver provided the subject with a feeling of support when completing the interview as well as helping to clarify or elaborate on the subject's responses to the questions. Subjects were not permitted to keep the videos or pamphlets until the end of the study.

At all 3 in-person interviews, subjects were asked to demonstrate how they used their inhalers, and this was verified by 2 observers (the facilitator and study coordinator). In addition, they were asked to also talk through the steps, explaining in their own words what they were doing, as if they were teaching a friend or family member how to use the inhaler. Other questions included whether they had ever received instructions demonstrating inhaler use, and if yes, by whom (eg, their doctor, a pharmacist, an asthma educator, or another health professional) and whether the demonstration was accompanied by print material or another medium. The bilingual facilitators received training on how to conduct interviews and the educational intervention and how to address community challenges and concerns regarding asthma self-management. They were encouraged not to dismiss traditional practices of community members but to integrate them. The study coordinator attended all interviews to reduce the likelihood of observational errors and took notes of subjects' comments and demonstrations of inhaler techniques during the interviews. The combined notes were reviewed at the end of each interview for clarity, precision, and necessary adjustment.

\section{Statistical Analysis}

Analyses were completed using SAS 17 (SAS Institute, Cary, North Carolina). We added up the Mandarin and Cantonese subjects in one group as "Chinese" to compare the objectives of interest with the "Punjabi" subjects. The outcomes of interest were (1) participants' ability to use inhalers (assessed through observation) and (2) understanding of physicians' instructions on asthma therapy (selfreported medication adherence). Analysis of variance was 


\section{Culturally Specific Evaluation of Inhaler Techniques in Asthma}

used to compare the effect of the educational materials on key outcomes across the 4 study groups. Analysis of covariance was used to adjust outcomes for age, sex, and educational level and to compare the pamphlet and video methods.

\section{Results}

\section{Participants' Characteristics}

Eighty-seven subjects were randomized into the intervention, and 85 completed the study (42 Chinese and 43 Punjabi, age $21-87$ y [mean \pm SD $62.9 \pm 15.3$ y], 42 males and 43 females) (Table 1). Table 1 includes the number for each group based on ethnicity and demographics of participants. Despite having controller and reliever medications at home, 39 participants $(45.8 \%)$ used only a reliever dry powder inhaler or puffer whenever needed, 41 participants $(48.2 \%)$ used both controller and reliever inhalers, and 5 participants $(5.9 \%)$ used 3 different inhalers. Overall, $54 \%$ of the participants used more than one inhaler for their asthma. Of all participants, $22(26 \%)$ claimed to have never received any oral or written instructions on how to use an inhaler from either their doctor, pharmacist, or asthma educator. From those who did receive instructions, only $16(19 \%)$ received information more than once, and $47(55 \%)$ received information on only one occasion when starting their medication with no subsequent follow-up test of their inhaler techniques.

\section{Comparison of Pretest and Follow-Up Test Data}

In this paper, we compared the results from pretest to follow-up test to ensure that we identified the changes occurring over time. Initial pretest assessments showed no statistically significant differences between the 2 ethnic groups in terms of age, sex, and educational level in relation to the outcomes of interest.

At the pretest interview, only 17 (20\%) of all participants used their inhaler(s) correctly (applied at least 7 steps correctly). Common mistakes were subjects not breathing out before inhaling and not holding their breath for $10 \mathrm{~s}$ after inhaling the medication or not shaking their metered-dose inhaler at the beginning of the procedure. The proportion of participants using the inhaler correctly increased to $42.4 \%(n=36)$ at the follow-up test. Group 1 , who watched the physician-led video, showed the biggest improvement of $51 \%$ in their mean correct inhaler steps in a follow-up test compared with the pretest (Table 2). In addition, the rate of correct use of the inhaler (at least 7 steps) at the follow-up test improved to $61.1 \%$ among Chinese subjects compared with $37.8 \%$ for Punjabi subjects $(P<.001)$. Furthermore, at the pretest for the 46 participants who used more than one medication, only 19
Table 1. Characteristics of the Patients Who Completed the Interventions

\begin{tabular}{|c|c|}
\hline Characteristics & Values \\
\hline \multicolumn{2}{|l|}{$\operatorname{Sex}, n(\%)$} \\
\hline Male & $42(49.4)$ \\
\hline Female & $43(50.6)$ \\
\hline \multicolumn{2}{|l|}{ Experimental and comparison groups, $n(\%)$} \\
\hline Group 1 (watched physician-led video) & $22(25.9)$ \\
\hline Chinese & $12(54.6)$ \\
\hline Punjabi & $10(45.4)$ \\
\hline Group 2 (watched community video) & $21(24.7)$ \\
\hline Chinese & $11(52.4)$ \\
\hline Punjabi & $10(47.6)$ \\
\hline $\begin{array}{l}\text { Group } 3 \text { (watched both community and } \\
\text { physician-led videos) }\end{array}$ & $20(23.5)$ \\
\hline Chinese & $9(45)$ \\
\hline Punjabi & $11(55)$ \\
\hline Group 4 (read pamphlet only) & $22(25.9)$ \\
\hline Chinese & $10(45.5)$ \\
\hline Punjabi & $12(54.5)$ \\
\hline \multicolumn{2}{|l|}{ Education, $n(\%)$} \\
\hline Never attended formal school & $15(17.6)$ \\
\hline Completed elementary school & $21(24.7)$ \\
\hline Completed high school & $29(34.1)$ \\
\hline Post-high school education & $20(23.5)$ \\
\hline \multicolumn{2}{|l|}{ Ethnicity, $n(\%)$} \\
\hline Chinese & $42(49)$ \\
\hline Punjabi & $43(51)$ \\
\hline Age, mean \pm SD y & $62.9 \pm 15.3$ \\
\hline \multicolumn{2}{|l|}{ Current employment status, $n(\%)$} \\
\hline Employed & $18(21.2)$ \\
\hline Unemployed & $25(29.4)$ \\
\hline Retired & $37(43.5)$ \\
\hline Volunteer job & $5(5.9)$ \\
\hline \multicolumn{2}{|l|}{ Medications taken, $n(\%)$} \\
\hline Inhaled steroids & $23(27)$ \\
\hline Long-acting bronchodilators & $7(8)$ \\
\hline Combination medications & $46(54)$ \\
\hline Short-acting bronchodilators & $48(56)$ \\
\hline \multicolumn{2}{|l|}{ Asthma action plan, $n(\%)$} \\
\hline Never received a written action plan from doctor & $59(69.4)$ \\
\hline Have received verbal information from doctor & $7(8.2)$ \\
\hline Have received written action plan from doctor & $3(3.5)$ \\
\hline No response (no data) & $16(18.8)$ \\
\hline Regular use of prescribed medications, $n(\%)$ & $60(82)$ \\
\hline Can distinguish reliever and controller inhaler, $n(\%)$ & $27(32)$ \\
\hline
\end{tabular}

$(41.3 \%)$ used them in the correct order ( $\beta_{2}$ agonists first). The results reveal that the proportion of participants using medications in the correct order improved significantly at the follow-up test, with no statistically significant differences identified between Chinese and Punjabi participants' inhaler technique improvements. The participants in both ethnic groups were able to express an understanding of 


\section{Culturally Specific Evaluation of Inhaler Techniques in Asthma}

Table 2. Mean Summary Score: Proper Use of an Inhaler, Pretest to Follow-Up, All Patients

\begin{tabular}{lcccc}
\hline \hline Study Group & $\begin{array}{c}\text { Pretest } \\
(\text { Mean } \pm \text { SD) }\end{array}$ & $\begin{array}{c}\text { Follow-Up Test } \\
(\text { Mean } \pm \text { SD) }\end{array}$ & $\begin{array}{c}\text { Change Over } \\
\text { Time }(\%)\end{array}$ & $P$ \\
\hline Group 1 & $4.5 \pm 2.0$ & $6.8 \pm 2.0$ & 51 & $<.001$ \\
Group 2 & $4 \pm 2.1$ & $5.9 \pm 2.0$ & 47.5 & .21 \\
Group 3 & $4.9 \pm 2.1$ & $6.8 \pm 1.6$ & 38.8 & .38 \\
Group 4 & $4.8 \pm 2.3$ & $5.6 \pm 1.4$ & 16.7 & .49
\end{tabular}

Table 2 results include both ethnic groups $(N=85)$. The observational checklist used a score of $0-9$. For comparisons between pretest and follow-up test, there was a statistically significant difference in mean score of correct use of inhaler among all participants over time $(P<.001)$. The biggest improvement was observed in Group 1 (who watched the physicianled video). Comparison across the 4 study groups was not statistically significant $P=.37$.

Table 3. Subgroup Analyses of Proper Use of an Inhaler and Understanding Physician Instructions

\begin{tabular}{|c|c|c|}
\hline Study Group & $\begin{array}{c}\text { Proper Use of an Inhaler, } \\
\text { Mean }(95 \% \mathrm{CI}) \\
P<.001\end{array}$ & $\begin{array}{c}\text { Understanding Physician } \\
\text { Instructions on Medication } \\
\text { Use, Mean }(95 \% \mathrm{CI}), P<.05\end{array}$ \\
\hline Group 1 & $2.71(1.35-4.06)$ & $0.53(0.12-0.94)$ \\
\hline Group 2 & $1.95(0.99-2.91)$ & $0.38(-0.06$ to 0.82$)$ \\
\hline Group 3 & $1.53(0.66-2.40)$ & $0.24(-0.19$ to 0.66$)$ \\
\hline Group 4 & $1.05(-0.10$ to 2.20$)$ & $0.35(-0.22$ to 0.92$)$ \\
\hline
\end{tabular}

Table 3 results include both ethnic groups $(N=85)$. Boldface values represent the largest changes observed between pretest and postintervention (follow-up test). Generally speaking, proper use of the inhaler and understanding of physicians' instructions improved significantly among all 4 groups from pretest to follow-up posttest. However, the biggest improvement in both measures was observed in Group 1 (who watched the physician-led video) at $P<.001$ and $P=.001$.

why they were using each one and the purpose of taking their medications. Finally, at pretest we noticed that only 15 out of the 71 participants $(21.2 \%$ who were using inhaled coricosteroids) only sometimes rinsed their mouth after inhaling their medication. While at follow-up test, we observed that the education provided in the videos and pamphlets had a significant effect on mouth rinsing in both ethnicity groups, with the proportion rinsing their mouth increased to $74.7 \%(n=53)$.

\section{Inhaler Use Technique}

Although there was no statistically significant difference in the correct use of inhalers across the 4 study groups over time (from pretest to follow-up test), proper use of inhalers improved significantly among the 4 experimental groups in the follow-up test $(P<.001)$. The biggest improvement was observed in Group 1 (Tables 2 and 3). Female subjects showed greater improvements compared with male subjects $(P=.047)$. In addition, Chinese subjects showed significantly greater improvements compared with Punjabi subjects $(P<.001)$. There were no statisti-
Table 4. Subgroup Analyses of Proper Use of an Inhaler and Understanding Physicians' Instructions

\begin{tabular}{lccc}
\hline \hline \multicolumn{1}{c}{ Outcomes of Interest } & $\begin{array}{c}\text { Observed } \\
\text { Mean }\end{array}$ & $P$ & $95 \%$ CI \\
\hline $\begin{array}{l}\text { Proper use of inhaler (according } \\
\quad \text { to standard checklist) }\end{array}$ & & & \\
$\quad$ Study group & 0.63 & .37 & -0.27 to 1.53 \\
Ethnicity & -1.40 & $<.001$ & -2.87 to 0.07 \\
Sex & 0.77 & .047 & -0.64 to 2.18 \\
Age & -0.09 & .43 & -0.31 to 0.13 \\
Education level & 0.71 & .09 & -0.11 to 1.53 \\
Understanding physician & & & \\
$\quad$ instructions & & & \\
$\quad$ Study group & 0.61 & .039 & -0.28 to 1.50 \\
Ethnicity & 0.27 & .15 & 0.09 to 0.45 \\
Sex & 0.61 & .049 & -0.06 to 1.28 \\
Age & -0.007 & .21 & -0.11 to 0.09 \\
Education level & 0.18 & .38 & -0.84 to 1.20
\end{tabular}

Table 4 results include both ethnic groups $(N=85)$. Difference in estimated mean scores for both ethnic groups (pretest vs postintervention follow-up test) and corresponding $95 \% \mathrm{CI}$ are shown. Negative estimated means depend on the order of comparisons, as follows: Assessment period $=$ intervention time comparing pretest with follow-up posttest for Groups 1,2 , and 3 versus Group 4; Study group = comparing video groups with the pamphlet group across-group comparison; Ethnicity = comparing Punjabi with Chinese; Age = comparing $<60$ y with $\geq 60$ y; Sex $=$ comparing female with male; Educational level $=$ comparing high school diploma and higher education with less than high school diploma education.

cally significant differences based on age and education level of the participants (Table 4).

\section{Understanding Physician's Instructions}

Subjects' understanding of physicians' instructions regarding asthma therapy (following the treatment regimen and regular use of inhalers [self-reported adherence]) improved significantly in all participants in the 4 groups over time $(P<.008)$. Group 1, who watched the physician-led video, showed the most improvement compared with the other 3 groups $(P=.039)$ (see Tables 3 and 4$)$. In addition, female subjects showed significant improvements over time in their understanding of physicians' instructions compared with male subjects $(P=.049)$. Notably, no significant differences were identified between Chinese and Punjabi participants, even when accounting for the subjects' education level and age, in terms of understanding physicians' instructions regarding their treatment regimen (see Table 4).

\section{Discussion}

In this randomized, controlled trial, we investigated whether inhaler techniques and understanding of physicians' instructions regarding asthma therapy could be improved with education provided in culturally appropriate videos and written pamphlets. Our anticipation was that 
more benefits would emerge if useful information was presented by trusted professionals (including the physician who came from a similar cultural background) in video format and if health materials were developed with the direct involvement of subjects. We were also interested in assessing differences across the ethnicity, education, age, and sex groups. Different studies have shown chronic diseases in minority communities to be normally managed within the family and social context, which could also be applied in asthma management. A unique feature of this study was that it was designed with the direct involvement of the community (subjects and their family members) and professional input on intervention design, material development, and implementation. In addition, the immediate caregiver at home was invited to attend the educational intervention, reinforcing a commitment from both the subjects and the trusted family member in self-management practices. In other studies, education information and interventions have been developed solely by health-care providers or by agencies without community engagement. ${ }^{12,27-30}$ The findings of our study showed the benefit of involving family caregivers not only in developing culturally and linguistically appropriate asthma information but also in applying the information in self-management practices.

Our study supports previous research indicating that most participants do not use their asthma inhaler correctly. ${ }^{14,15}$ Furthermore, we showed that inhaler technique can be significantly improved after instructions given by trusted sources using culturally and linguistically relevant educational information. In terms of the effect of ethnicity on proper use of the inhaler, we noticed that inhaler use techniques improved more significantly in Chinese participants compared with the Punjabi participants. Two important factors may have been at play. The first could be related to the age of the participants; Punjabi participants were relatively older than the Chinese participants. The second factor could be related to educational levels ${ }^{14}$; Punjabi participants had lower levels of formal education than the Chinese participants. Our data showed that in both ethnic groups, younger participants who had higher levels of formal education showed significant improvements in understanding both physician instructions and inhaler techniques compared with older and less educated participants. This finding suggests that the interaction of age, education level, and knowledge may influence one's correct use of an inhaler to prevent loss of control of asthma across ethnocultural groups. Further studies with larger samples should account for the role of aging and cognitive decline in the learning styles of different ethno-cultural groups as well as the possible role of sex in medically related skill-based learning.

Inadequate inhaler technique has been previously reported and can be explained by several factors. (1) Partic- ipants are often given insufficient or no instruction on the correct use of an inhaler. ${ }^{11-13}$ In our study, $26 \%$ of the participants reported receiving no previous instruction despite using their inhalers for an extended period. Four participants put the metered-dose inhaler in their nose, suggesting that they had never received instructions on how to use the prescribed drug at all. (2) Older participants, in particular those suffering from severe air flow obstruction, were often unable to inhale dry powder inhalers adequately. ${ }^{4,15}$ Some studies reported that observed patient inhaler techniques might be even worse than the score given because the observer may not be able to detect certain mistakes. ${ }^{1,12}$ In our study, we reduced the likelihood of such errors with 2 observers simultaneously assessing inhaler techniques during the interviews, a novel observational research approach that has rarely been used before. At the completion of the final assessment, the facilitator and study coordinator responded to asthma-related concerns and questions from all subjects in the 4 study groups.

\section{Limitations}

We believe that our sample size does not have the breadth to generalize certain ethno-cultural communities' cultural norms and health behavior. In addition, it is not clear to what extent the subjects studied are representative of all asthma patients in the target communities using asthma medication. Furthermore, reliance on self-reported adherence may leave the results susceptible to response biases, such as social desirability bias. However, participation of 97\% of the enrolled subjects to complete the study confirms that adults with asthma from Punjabi, Cantonese, and Mandarin communities are interested in taking an active role in their self-management and in participating in a health education intervention that can be integrated into routine asthma care.

\section{Conclusions}

Patients from ethno-cultural communities may feel misjudged and diminished by a care provider or health-care system that tends to represent a biomedical worldview, which might differ from patients' perspectives. The way in which information is developed and presented by healthcare providers may facilitate or hinder understanding and use of such information, which would eventually affect self-management of asthma. We developed culturally and linguistically appropriate communication styles to provide needed information that differs from conventional intervention because we involved the subjects in the development and approval of the information materials, including input for the content and the meaning and messages within the educational materials. In addition, we provided the 


\section{Culturally Specific Evaluation of Inhaler Techniques in Asthma}

information in a format suggested initially by the subjects (ie, video), and it was performed by health-care professionals and peer subjects who speak the same language as their communities. We noticed that applying socially and culturally attuned interactive communication styles to develop physician-led or subject role-played video-based materials was effective in improving participants' proper use of inhalers and self-confidence in following physicians' instructions. Therefore, we recommend that health educators and professionals who are involved in the care of asthma patients tailor the informational materials based on the cultural perspectives of the target community as well as developing information in a short video presentation format. Such practices may enable patients to develop and strengthen their sense of self-efficacy and confidence in relation to managing their chronic disease and to perceive information as being relevant to their socio-cultural reality. In addition, the role of family members in self-management practices should be considered in any educational program as an incentive for subjects to follow up the treatment therapy. Although the methods and results reported here were encouraging, future research is required to evaluate the impact of our educational interventions on health service utilization and clinical outcomes.

\section{ACKNOWLEDGMENTS}

We thank the community members, facilitators, immigrant-serving agencies, and key informants from the Punjabi and Chinese communities in the greater Vancouver area who helped us from the initial steps of this research. We also kindly appreciate the Chinese and Punjabi physicians for contributions to the development of the educational videos. Also, we acknowledge Emma FitzGerald for completing the patient educational pamphlet illustrations.

\section{REFERENCES}

1. Levy ML, Hardwell A, McKnight E, Holmes J. Asthma patients' inability to use a pressurised metered-dose inhaler (pMDI) correctly correlates with poor asthma control as defined by the Global Initiative for Asthma (GINA) strategy: a retrospective analysis. Prim Care Respir J 2013;22(4):406-411.

2. Crompton GK, Barnes PJ, Broeders M, Corrigan C, Corbetta L, Dekhuijzen $\mathrm{R}$, et al. The need to improve inhalation technique in Europe: a report from the Aerosol Drug Management Improvement Team. Respir Med 2006;100(9):1479-1494.

3. Fuller-Thomson E, Robertson A, Chaudhuri N, Purdon L, Thompson M. 1998. Towards respiratory health in South East Toronto: Life histories of Chinese and Caribbean immigrants (Final Report). Toronto: Joint Center of Excellence for Research on Immigration and Settlement. Accessed December 28, 2014.

4. Al-Jahdali H, Ahmed A, Al-Harbi A, Khan M, Baharoon S, Bin Salih $\mathrm{S}$, et al. Improper inhaler technique is associated with poor asthma control and frequent emergency department visits. Allergy Asthma Clin Immunol 2013;9(1):8.

5. Giraud V, Roche N. Misuse of corticosteroid metered-dose inhaler is associated with decreased asthma stability. Eur Respir J 2002;19(2): 246-251.

6. Lavorini F, Magnan A, Dubus JC, Voshaar T, Corbetta L, Broeders $\mathrm{M}$, et al. Effect of incorrect use of dry powder inhalers on manage- ment of patients with asthma and COPD. Respir Med 2008;102(4): 593-604.

7. Bailey EJ, Cates CJ, Kruske SG, Morris PS, Brown N, Chang AB Culture-specific programs for children and adults from minority groups who have asthma. Cochrane Database Syst Rev 2009;(4):115.

8. Bahadori K, Quon BS, Doyle-Waters MM, Marra C, Fitzgerald JM. A systematic review of economic evaluations of therapy in asthma. J Asthma Allergy 2010;3:33-42.

9. Sadatsafavi M, Lynd L, Marra C, Carleton B, Tan WC, Sullivan S, Fitzgerald JM. Direct health care costs associated with asthma in British Columbia. Can Respir J 2010;17(2):74-80.

10. Global Initiative for Asthma (GINA). Global Strategy for Asthma Management and Prevention. December 2011. http://erj.ersjournals.com/ content/31/1/143.full.pdf + html. Accessed July 18, 2016.

11. Smeeton NC, Rona RJ, Gregory J, White P, Morgan M. Parental attitudes towards the management of asthma in ethnic minorities. Arch Dis Child 2007:92(12):1082-1087.

12. Cabana MD, Slish KK, Evans D, Mellins RB, Brown RW, Lin X, et al. Impact of physician asthma care education on patient outcomes. Pediatrics 2006;117(6):2149-2157

13. Edgren KK, Parker EA, Israel BA, Lewis TC, Salinas MA, Robins TG, Hill YR. Community involvement in the conduct of a health education intervention and research project: community action against asthma. Health Promot Pract 2005;6(3):263-269.

14. Janson SL, McGrath KW, Covington JK, Cheng SC, Boushey HA. Individualized asthma self-management improves medication adherence and markers of asthma control. J Allergy Clin Immunol 2009; 123(4):840-846.

15. Centers for Disease Control and Prevention. Vital signs: asthma prevalence, disease characteristics, and self-management education: United States, 2001-2009. MMWR Morb Mortal Wkly Rep 2011; 60(17):547-552.

16. Yin HS, Gupta RS, Tomopoulos S, Wolf MS, Mendelsohn AL, Antler L, et al. Readability, suitability, and characteristics of asthma action plans: examination of factors that may impair understanding. Pediatrics 2013;131(1):e116-e126.

17. Sampson A. Culturally and linguistically appropriate health education materials: access, networks, and initiatives for the future: an exploration: the cross culture healthcare program (CCHCP) 2007. Seattle, Washington. http://healthequity.wa.gov/Portals/9/Doc/Publications/Reports/ HDC-Reports-CCHCP.pdf. Accessed July 18, 2016.

18. Kara Kaşıkç M, Alberto J. Family support, perceived self-efficacy and self-care behaviour of Turkish patients with chronic obstructive pulmonary disease. J Clin Nurs 2007;16(8):1468-1478.

19. Mangan JM, Wittich AR, Gerald LB. The potential for reducing asthma disparities through improved family and social function and modified health behaviors. Chest 2007;132(5 Suppl):789S-801S.

20. Poureslami IM, Rootman I, Balka E, Devarakonda R, Hatch J, FitzGerald JM. Systematic review of asthma and health literacy: a cultural-ethnic perspective in Canada. MedGenMed 2007;9(3): 40-48.

21. Boulet LP, McIvor RA, Marciniuk D, Canadian Thoracic Society Respiratory Guidelines Committee. Respiratory guidelines implementation in Canada. Can Respir J 2007;14(6):329-330.

22. Asthma Society of Canada. How to use your inhaler. 2014. http:// www.asthma.ca/adults/treatment/meteredDoseInhaler.php. Accessed July 18, 2016.

23. Public Health Agency of Canada. Life and breath: respiratory disease in Canada. 2007. http://www.phac-aspc.gc.ca/publicat/2007/lbrdcvsmrc/index-eng.php\#tphp. Accessed July 18, 2016.

24. Poureslami I, Rootman I, Doyle-Waters MM, Nimmon L, Fitzgerald JM. Health literacy, language, and ethnicity-related factors in new- 


\section{Culturally Specific Evaluation of Inhaler Techniques in Asthma}

comer asthma patients to Canada: a qualitative study. J Immigr Minor Health 2011;13(2):315-322.

25. Poureslami I, Nimmon L, Doyle-Waters MM, FitzGerald JM. Using community-based participatory research (CBPR) with ethno-cultural groups as a tool to develop culturally and linguistically appropriate asthma educational material. Divers Health Care 2011;8:203-215.

26. Poureslami I, Doyle-Waters M, Nimmon L, Shum J, FitzGerald JM. Hearing community voice: methodological issues in developing asthma self-management educational materials for immigrant communities. In: Agyemang C, Airhihenbuwa CO, and de-Graft Aikins A, editors. Ethnicity: theories, international perspectives and challenges. 1st edition. New York: Nova Science Publishers; 2013:183-202.
27. Zayas LE, McLean D. Asthma patient education opportunities in predominantly minority urban communities. Health Educ Res 2007; 22(6):757-269

28. Inkelas M, Garro N, McQuaid EL, Ortega AN. Race, ethnicity, language, and asthma care: findings from a 4-state survey. Ann Allergy Asthma Immunol 2008;100(2):120-127.

29. Fink JB, Rubin BK. Problems with inhaler use: a call for improved clinician and patient education. Respir Care 2005;50(10):1360-1374; discussion 1374-1375.

30. Shah S, Peat JK, Mazurski EJ, Wang H, Sindhusake D, Bruce C, et al. Effect of peer led programme for asthma education in adolescents: cluster randomised controlled trial. BMJ 2001;322(7286):583-588.

This article is approved for Continuing Respiratory Care Education credit. For information and to obtain your CRCE

(free to AARC members) visit

www.rcjournal.com 